\title{
Soledad Reyes del Villar, Manuel Rodríguez. Aún tenemos patria, Santiago, Ediciones El Mercurio, 2018, 173 págs.
}

El libro Manuel Rodríguez. Aún tenemos patria surge para recordar el bicentenario de la muerte del guerrillero y de paso desmitificar a una de las leyendas más intrigantes de la historia chilena.

Sorprende de modo grato la excelente narración, análisis y reflexión que realiza la autora al momento de aproximarse a la vida de Manuel Rodríguez a través de una visión historiográfica no desde las fuentes archivísticas, algo que de verdad es una deuda en este excelente texto y que hubiera fortalecido el desarrollo del libro al hacerlo aún más novedoso.

Las fortalezas de este trabajo son múltiples, pero nos quedaremos con dos. La primera, la importancia y la novedad del estudio. Reyes nos muestra una nueva visión sobre el prócer chileno hasta el momento desconocida, un Manuel Rodríguez que fue aficionado a las peleas de gallo, los juegos de naipe, el billar y a los romances con las mujeres, convirtiendo el libro en llamativo e interesante.

Por último, la capacidad de análisis. La historiadora elabora interesantes conjeturas a partir de temas como la relevancia de la vida colonial, los primeros años de la Independencia, las batallas y la leyenda en torno a la muerte de
Manuel Rodríguez.

Respecto a su estructura, se divide en dos partes. En la primera, Reyes se encarga de contar la vida de Manuel Rodríguez, quiénes fueron sus padres, las diversiones de Rodríguez y sus hermanos, su educación en el colegio de San Carlos (Carolino), la vida de la sociedad colonial que rondaba entre los comerciantes ambulantes y sus novedades, telas, charqui, olitas, las clases bajas en Santiago y la vida cómoda de la sociedad aristocrática, destacando en detalles que rara vez los historiadores se detienen en analizar.

En la segunda parte, la autora se centra en la participación militar de Manuel Rodríguez. Acá destacan su servicio en la lucha independentista hasta 1814 y su emigración hacia Argentina junto a Carrera y O'Higgins, tras la derrota en el desastre de Rancagua. Posteriormente se analiza la función de espía de Manuel Rodríguez al servicio de San Martín tras volver a Chile, la organización y reclutamiento de hombres, la lucha en contra de los realistas y su fama entre la gente.

Si bien la autora reconstruye las tareas militares que realizó el guerrillero en Chile, pareciera más interesante detenerse en las instancias en que las luchas independentistas se acaban y San Martín

Jorge Orellana

Soledad Reyes del Villar, Manuel Rodríguez. Aún tenemos patria, Santiago, Ediciones El Mercurio, 2018, 173 págs. Autoctonía. Revista de Ciencias Sociales e Historia, Vol. III, N² 2, Julio-Diciembre 2019, 298-299

ISSN 0719-8213

DOI: http://doi.org/10.23854/autoc.v3i2.128 
y O'Higgins deciden deshacerse de Manuel Rodríguez y los hermanos Carrera, por considerarlos una amenaza al Estado que se estaba creando en Chile. Esto motivó que Bernardo O'Higgins ordenara a San Martín que ejecutara a los hermanos de José Miguel Carrera, Juan José y Luis, elemento que despertó el deseo de venganza de Carrera y de su amigo Manuel Rodríguez, quien se dirige, junto a un grupo de personas, hasta la casa de Bernardo O'Higgins para gritar insultos en contra de él. Esto le significó ser arrestado y conducido al cuartel de los Cazadores de los Andes en Chile. Soledad Reyes se adentra en los últimos días de Manuel Rodríguez, su escape de la prisión, su intención de fugarse a Estados Unidos para evitar que lo encuentren O'Higgins y San Martín y, finalmente, el asesinato del guerrillero. Aquí la narración es muy descriptiva: se detalla que al momento del disparo, Rodríguez vestía una chaqueta verde con trencillas negras, pantalón y gorra militar. Después lo arrastraron hacia un zanjón y lo cubrieron con ramas y piedras, cerca de un cementerio indígena. Elemento importante a destacar, y que convierte al libro en una novedad para el lector, es que no se conoce cómo fue realmente el asesinato de Rodríguez.

Finalmente, la historiadora desentraña el enigma de qué ocurrió con los restos de Manuel Rodríguez. Se cuenta que el párroco Sancho Montiel lo enterró en el centro del presbiterio, al costado izquierdo del altar. El juez le pidió a los asistentes que guardaran el secreto por temor a las represalias del gobierno o' higginista.
Pasaron muchos años sin que nadie supiera dónde estaba enterrado Manuel Rodríguez. Pero el juez Tomás Valle tenía la respuesta, relatando que fueron enterrados en la capilla de Til Til. De esta forma, en 1894, un comité formado por Enrique Allende, Justo Abel Rosales y Abelardo Carvajal le piden al presidente Jorge Montt autorización para exhumar los restos del guerrillero y llevarlos al Cementerio General en Santiago de Chile, donde fue recibido con honores militares y reposa hasta el día de hoy. Finalmente, la autora comenta que no se sabe cómo ni cuándo se aclarará la verdad sobre la vida y muerte de Manuel Rodríguez. La reflexión final de Soledad Reyes es interesante de exponer: "que la leyenda no opaque el legado que realmente dejó a este país".

En síntesis, estamos ante una biografía de Manuel Rodríguez escrita con una pluma amena, destinada a historiadores y a un público culto lector de historia. En cuanto a la estructura de los capítulos, falta señalar los objetivos que persiguen y además establecer un resumen que permita repasar las ideas principales que se han presentado en el libro. Para la historiografía chilena es un aporte de lo que hasta ahora se conoce y se ha escrito sobre el guerrillero.

Jorge Orellana Billiard Universidad Diego Portales 